\title{
Therapeutic Development of Apolipoprotein E Mimetics for Acute Brain Injury: Augmenting Endogenous Responses to Reduce Secondary Injury
}

\author{
Michael L. James ${ }^{1,2,3}$ • Jordan M. Komisarow ${ }^{4}$ Haichen Wang ${ }^{2}$ • Daniel T. Laskowitz ${ }^{1,2,3,4}$
}

Published online: 21 April 2020

(C) The American Society for Experimental NeuroTherapeutics, Inc. 2020

\begin{abstract}
Over the last few decades, increasing evidence demonstrates that the neuroinflammatory response is a double-edged sword. Although overly robust inflammatory responses may exacerbate secondary tissue injury, inflammatory processes are ultimately necessary for recovery. Traditional drug discovery often relies on reductionist approaches to isolate and modulate specific intracellular pathways believed to be involved in disease pathology. However, endogenous brain proteins are often pleiotropic in order to regulate neuroinflammation and recovery mechanisms. Thus, a process of "backward translation" aims to harness the adaptive properties of endogenous proteins to promote earlier and greater recovery after acute brain injury. One such endogenous protein is apolipoprotein $\mathrm{E}(\mathrm{apoE})$, the primary apolipoprotein produced in the brain. Robust preclinical and clinical evidence demonstrates that endogenous apoE produced within the brain modulates the neuroinflammatory response of the acutely injured brain. Thus, one innovative approach to improve outcomes following acute brain injury is administration of exogenous apoEmimetic drugs optimized to cross the blood-brain barrier. In particular, one promising apoE mimetic peptide, $\mathrm{CN}-105$, has demonstrated efficacy across a wide variety of preclinical models of brain injury and safety and feasibility in early-phase clinical trials. Preclinical and clinical evidence for apoE's neuroprotective effects and downregulation of neuroinflammatory and the resulting translational therapeutic development strategy for an apoE-based therapeutic are reviewed.
\end{abstract}

Key Words Apolipoprotein E $\cdot$ Mimetic peptides $\cdot$ Neuroinflammation $\cdot$ Acute brain injury $\cdot$ Therapeutic development $\cdot$ Stroke

\section{Neuroinflammation: the Brain's Endogenous Response to Injury}

Acute central nervous system (CNS) injury resulting from cerebrovascular disease and trauma is associated with

Electronic supplementary material The online version of this article (https://doi.org/10.1007/s13311-020-00858-x) contains supplementary material, which is available to authorized users.

Daniel T. Laskowitz

daniel.laskowitz@duke.edu

1 Duke Clinical Research Institute, Duke University School of Medicine, Durham, NC, USA

2 Department of Neurology, Duke University School of Medicine, Durham, NC, USA

3 Department of Anesthesiology, Duke University School of Medicine, Durham, NC, USA

4 Department of Neurosurgery, Duke University School of Medicine, Durham, NC, USA significant morbidity and mortality [1]. Decades of advances in fundamental knowledge of basic cellular and molecular mechanisms associated with primary and secondary acute neuronal injury have led to a host of potential therapeutic targets and compounds. However, none of these pharmacological interventions have translated into effective therapies with proven efficacy on either reduction in death or improved neurobehavioral recovery in human injury [2]. Supportive neurocritical care remains the mainstay of early management for patients with acute CNS injury, with minimal improvement in mortality rates over the last two decades [3, 4]. Thus, a clear and urgent unmet clinical need exists for development of innovative neuroprotective therapeutics for such patients. New development strategies are required if the translational "valley of death" is to be crossed.

Traditionally, new therapeutic strategies have utilized a reductionist approach, and focused on cell-specific, individual target receptors discovered from our increased mechanistic understanding of disease-specific pathophysiology. While the importance of cell- and disease-specific mechanisms is 
obvious, therapeutic development for CNS injury has been limited by the hunt for the "silver bullet." However, pleiotropic compounds might heighten the potential for successful translation by targeting several mechanisms across multiple cell types interconnected by a salient brain response. For example, neuroinflammation serves as a common denominator brain response that exacerbates secondary neuronal injury in a variety of acute and chronic neuropathologies. Moreover, in the setting of acute CNS injury, neuroinflammation plays an important role in mediating secondary tissue injury for days after initial insult $[5,6]$; thus, the therapeutic window for such approaches may be wider than strategies solely targeting excitotoxicity. For these reasons, targeting neuroinflammatory responses for therapeutic development holds promise in the treatment of diverse forms of brain injury [7].

In the absence of infection, brain injury triggers immune reaction through microglial activation as a central factor in mediating neuroinflammatory responses, development of cerebral edema, and secondary neuronal death following acute CNS injury [8]. Activation of microglia and recruitment of peripheral mononuclear cells into the brain represent the cornerstone of the CNS neuroinflammatory response. Through initial release of damage-associated molecular pattern molecules, reactive oxygen species, and inflammatory cytokines, neuroinflammation has both adaptive and maladaptive effects on brain tissue survival and ultimate recovery [9]. This inflammatory cascade contributes to oxidative stress, secondary neuronal injury, blood-brain barrier breakdown, resulting cerebral edema, and tissue and cellular disruption. Microglial cells become activated within minutes of brain injury, and evidence supports a persistent chronic activation of microglia after initial injury $[10,11]$. After their initial activation, microglial cells secrete proinflammatory cytokines and chemokines, such as interleukins and tumor necrosis factor, which contribute to blood-brain barrier breakdown, leukocyte margination, the development of cerebral edema, and, ultimately, cellular dysfunction and death $[12,13]$. Although a variety of immunomodulatory strategies have been tried in the setting of acute CNS injury [14], no pharmacological interventions improve long-term neurobehavioral outcomes or mortality [2, 15]. Despite prior translational failures, future promise may lie in harnessing genetic influences known to modify acute CNS injury responses and recovery.

\section{APOE: Prototype of Genetic Association with Neuroinflammation}

One of the most robust genetic associations with outcome after acute CNS injury is apolipoprotein E (APOE-gene; apoE_-protein). Cumulative evidence suggests that APOE4 is associated with poor outcome after acute CNS injury [16, 17], although several conflicting reports exist on APOE's relationship with prognosis after subarachnoid hemorrhage $[18,19]$ and intracerebral hemorrhage [20, 21].

ApoE is the primary apolipoprotein produced within the brain, where its glial secretion is upregulated after injury. ApoE has three common human protein isoforms (designated apoE2, apoE3, and apoE4) which differ by single cysteine to arginine interchanges at residues 112 and 158 [22]. In addition to its role in cholesterol transport, biologically relevant concentrations of apoE modify glial activation and inflammatory cytokine release $[23,24]$. In fact, an established literature exists suggesting lipoproteins play a significant role in immune function and modulating inflammatory responses. For example, HDL-associated apoA-I modifies innate immune responses against foreign pathogens [25] and is essential for lipopolysaccharide (LPS) neutralization to protect against pathogenic LPS effects in preclinical models [26]. In addition, HDL plays a key role in downregulating systemic inflammation in preclinical models for several disease processes including sepsis, atherosclerosis, and lung injury [27-29]. Similarly, an extensive body of work has demonstrated that apoE plays an essential role in modulating host defenses and innate immune responses against foreign pathogens, both by modifying monocyte responses and by modulating $\mathrm{T}$ cell-mediated immune responses [30, 31]. A number of preclinical studies showing abnormal immune responses in apoE-deficient animals further substantiate a significant role for apoE in modulating the immune response and blood-brain barrier integrity [32-34].

Subsequent studies demonstrated that apoE may exert isoform-specific modulation of the inflammatory response of the injured CNS in the clinical setting [35]. In particular, the APOE4 polymorphism has been associated with increased systemic inflammatory responses [36] and delirium in the intensive care setting [37]. Further, presence of an APOE4 allele has been associated with poor neurobehavioral outcome in a number of acute clinical brain injuries, including increased cerebral edema after intracerebral hemorrhage [35], and poor functional outcome after subarachnoid hemorrhage [18], and traumatic brain injury [38]. These preliminary clinical observations are reinforced by murine models of brain injury demonstrating worse neurobehavioral outcomes and increased neuroinflammatory responses in the presence of the APOE4 allele [33, 39-42]. One plausible explanation for these isoform-specific effects is that apoE modulates glial activation and neuroinflammatory cascades in an isoform-specific fashion. Indeed, presence of the apoE4 isoform is associated with enhanced glial activation and secondary neuronal injury as compared to apoE3 in both in vitro and in vivo paradigms of acute brain injury $[42,43]$.

The exact mechanism(s) of apoE's influences in brain injury and recovery are not completely defined, although evidence suggests its interaction with the low-density lipoprotein receptor-related protein 1 (LRP-1), also known as alpha-2- 
macroglobulin receptor, apolipoprotein E receptor, or cluster of differentiation 91 (Fig. 1) [44]. The LRP-1 receptor, present on both glia and neurons, may be necessary to mediate antiinflammatory and neuroprotective effects of apoE [45]. This hypothesis is consistent with the fact that peptides containing the apoE receptor-binding region appear to bind LRP-1 and modulate N-methyl-aspartic acid (NMDA) receptor activity in neurons [46-49]. These same peptides also downregulate the inflammatory phenotype of microglia, an effect that is not observed in LRP1-deficient microglia [50]. Although apoE's polymorphic regions determining E2, E3, and E4 isoforms (cysteine to argine interchanges at positions 112 and 158) lie outside the receptor-binding region (residues 130-149), these polymorphisms clearly affect receptor binding. Notably, apoE3, but not apoE4, mediates LRP-1 dependent clearance of $A \beta$ [51], and reports have suggested impaired binding of apoE4 to LRP-1 in vivo [52]. Importantly, although LRP-1 is the presumed target receptor of apoE binding, it is only one of a family of low-density lipoprotein receptors that have significant overlap with regard to ligand binding.
Clinical relevance of the collective evidence of apoE's response to brain injury in preclinical modeling is suggested by use of APOE-targeted replacement mice expressing the human protein isoforms. Mice expressing human apoE4 have increased systemic and brain inflammatory responses following challenge with bacterial endotoxin [33]. Seminal observations have demonstrated that biologically relevant concentrations of apoE modify glial activation in cell culture [23, 24], an observation that was later extended to demonstrate isoform specificity [53]. These isoform-specific effects of apoE on inflammation are highly likely to be clinically relevant, as a pilot clinical study in patients with intracerebral hemorrhage demonstrated increased cerebral edema and worsened outcome associated with the APOE4 allele [35]. This finding was backward translated demonstrating humanized apoE4 association with increased cerebral edema and worse neurobehavioral outcome in preclinical models [49]. Moreover, targeted replacement animals expressing the apoE4 isoform have evidence of increased glial activation subsequent inflammation and worse behavioral outcomes than their apoE3
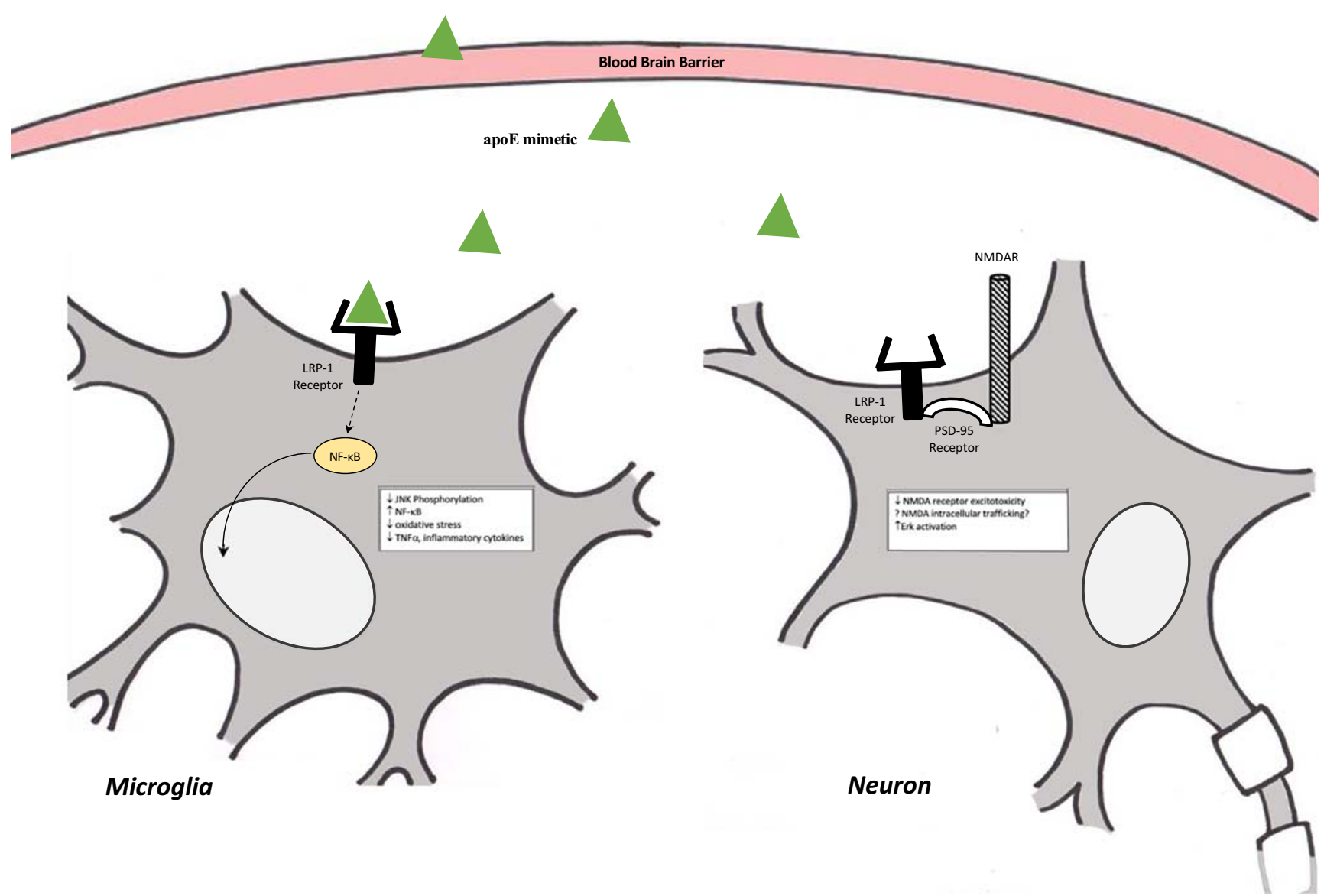

Fig. 1 Apolipoprotein E (apoE)-mimetic peptides, such as the pentapeptide $\mathrm{CN}-105$, are derived from apoE holoprotein receptorbinding region and have the ability to cross the blood-brain barrier. These peptides exhibit anti-inflammatory and neuroprotective responses after acute CNS injury by binding lipoprotein receptor-related protein 1

(LRP-1) on both microglia and neurons. Note: Erk, extracellular signalregulated kinase; JNK, c-Jun N-terminal kinase; NF-KB, nuclear factor kappa-light-chain-enhancer of activated B cells; NMDA, N-methyl-Daspartic acid; PSD-95, postsynaptic density protein 95 ; TNF, tumor necrosis factor 
counterparts in murine models of traumatic brain injury [42, $54]$ and subarachnoid hemorrhage [39, 55]. Despite the bulk of evidence of isoform-specific differences, whether apoE4 plays an active role in exacerbating maladaptive neuroinflammatory responses, i.e., "direct negative effect" or whether apoE4 interferes with the beneficial neuroprotective effects of apoE3, is unknown [43].

Finally, in addition to modulating neuroinflammatory responses, apoE and apoE-mimetic peptides exert direct neuronal protection from NMDA-mediated excitotoxicity [49, 56-58]. Several mechanisms have been proposed to explain the effects of apoE on NMDA function, including modulating function via the intracellular scaffolding protein PSD-95 and modulating intracellular trafficking $[59,60]$.

\section{Development of apoE-Based Therapies: Reverse Engineering a Neuroprotective Therapy}

Given the neuroprotective effects of apoE in the setting of acute CNS injury, one therapeutic strategy might be to administer exogenous apoE protein. However, the intact apoE holoprotein does not readily cross the blood-brain barrier (BBB), and is, thus, unsuitable for peripheral administration [61]. An innovative approach to improve outcomes following acute CNS injury is the administration of apoE-mimetic drugs designed to penetrate into the CNS compartment. To address this problem, we originally created a series of apoE-mimetic peptides derived from the apoE receptor-binding region (residues 130-150) [53, 62]. These peptides had robust efficacy in cell culture and improved neurobehavioral and histological endpoints in preclinical models of CNS inflammation and acute CNS injuries (see Table 1), including intracerebral and subarachnoid hemorrhage $[31,38,39,52,63]$ and both closed skull and cortical contusion models of brain trauma [63-67]. Most recently, a second generation of mimetic peptides were produced to improve CNS penetration after intravenous administration. $\mathrm{CN}-105$, a 5 -amino acid peptide derived from the binding face of the apoE receptor-binding region, is such a second-generation apoE-mimetic. $\mathrm{CN}-105$ is associated with increased potency and CNS penetration [63-65] and maintains the anti-inflammatory and neuroprotective functionality of the intact apoE protein. We have recently demonstrated that systemic administration of $\mathrm{CN}-105$ is well tolerated, and associated with a reduction in cerebral edema and improved neurobehavioral outcomes after intrastriatal collagenase injection model to induce intracerebral hemorrhage [68], as well as models of other related acute CNS pathologies such as subarachnoid hemorrhage [69-72], focal ischemia/reperfusion [73-76], and traumatic brain injury [77-79]. Finally, significant pharmacokinetics-pharmacodynamics dissociation for CN-105 effects in the brain. Although serum half-life of
CN-105 is short (30 min in rodents), durable pharmacodynamic effect occur when $\mathrm{CN}-105$ is administered after CNS injury, as evidenced by long-term improvement in neurological outcomes [78].

\section{Clinical Development: Phase 1 Study}

Based on promising preclinical results and safety data, $\mathrm{CN}$ 105 was selected for drug development to treat patients with acute CNS injuries. Following Investigational New Drug (IND) enabling studies, a first-in-human single ascending dose (SAD) and multiple dose placebo-controlled clinical trial was performed to define the safety and pharmacokinetics (PK) of CN-105 in healthy human adults (NCT02670824) [80], In the SAD portion of this first-in-human study, 8 participants were randomized to $\mathrm{CN}-105$ or saline control (6 active, 2 control) at $0.01,0.03,0.1,0.3$, and $1.0 \mathrm{mg} / \mathrm{kg}$ administered over $30 \mathrm{~min}$. In the multiple dose placebo-controlled clinical trial, additional subjects ( 6 active, 2 control) were randomized to receive $1.0 \mathrm{mg} / \mathrm{kg}$ at 6 -h intervals over 72 -h period. All 48 randomized subjects completed the study.

No significant safety issues were identified with either dosing regimen, and pharmacokinetic analysis revealed linearity without significant drug accumulation. The median half-life in the terminal elimination phase of $\mathrm{CN}-105$ following a single or repeated dosing regimen was approximately $3.6 \mathrm{~h}$, and did not appreciably change as a function of dosing. There was minimal drug accumulation after repeated 6-h intravenous doses, and steady state was achieved in the first $24 \mathrm{~h}$. CN105 was confirmed to have a linear and predictable pharmacokinetic profile in humans with minimal accumulation after repeat dosing. Importantly, in both the SAD and multiple dosing paradigms, administration of CN-105 was safe and well tolerated with no serious drug-related adverse events reported. Based on the results of this phase 1 study, a dose of $1 \mathrm{mg} / \mathrm{kg}$, administered intravenously at 6-h intervals for $72 \mathrm{~h}$, was selected for use in first-in-disease state phase 2 studies.

\section{Early Phase 2: the CATCH Study}

To prepare for more definitive studies in acute brain injury, our strategy was to first test the safety and feasibility of administering $\mathrm{CN}-105$ in patients with intracerebral hemorrhage, as this indication presents important features of traumatic pathology, and conferred several tactical advantages. Spontaneous (hypertensive) intracerebral hemorrhage represents a tractable initial clinical study; as it is a relatively homogeneous disease process, patients commonly present early after symptom onset, and are often accompanied by family members, thus facilitating informed consent. This initial study also allowed us to test the safety and 
Table 1 Evidence of $\mathrm{CN}-105$ efficacy in preclinical models

\begin{tabular}{|c|c|c|c|c|}
\hline Injury & Species & Histological/biochemical outcome measures & Functional outcome measures & References \\
\hline Stroke-MCAO & Rat & Reduction in infarct volume (35 days) & $\begin{array}{l}\text { Improved vestibulomotor function, locomotor } \\
\text { function }\end{array}$ & $\begin{array}{r}\text { Tukhovskaya } \\
\text { et al., } 2009\end{array}$ \\
\hline Stroke-MCAO & Mouse & $\begin{array}{l}\text { Reduced microglial activation, infarct volume, } \\
\text { improved survival }\end{array}$ & Improved vestibulomotor function & Tu et al., 2017 \\
\hline Hypoxia & Rat & Less tissue loss & Reduced mortality & $\begin{array}{l}\text { McAdoo et al., } \\
2005\end{array}$ \\
\hline Stroke-MCAO & Mouse & $\begin{array}{l}\text { Reduced infarct volume and radiographic } \\
\text { infarct progression }\end{array}$ & Improved vestibulomotor function & Wang et al. 2013 \\
\hline $\mathrm{ICH}$ & Mouse & Reduction in inflammatory cytokines, cerebral edema & Improved vestibulomotor function & James et al. 2009 \\
\hline $\mathrm{ICH}^{*}$ & Mouse & $\begin{array}{l}\text { Reduction in microgliosis, edema, neuronal injury, } \\
\text { inflammatory signaling (p38; NFKB) }\end{array}$ & Improved vestibulomotor function and memory & Lei et al., 2016 \\
\hline $\mathrm{SAH}^{*}$ & Mouse & Reduction in vasospasm, & Improved vestibulomotor & Liu et al., 2018 \\
\hline SAH & Mouse & Reduction in vasospasm, edema, mortality & $\begin{array}{l}\text { Improved functional exam, vestibulomotor } \\
\text { function }\end{array}$ & Gao et al.,2006 \\
\hline $\mathrm{SAH}$ & Mouse & Reduction in vasospasm & Improved vestibulomotor fun & Mesis et al.,2006 \\
\hline SAH & Mouse & $\begin{array}{l}\text { Reduced microgliosis and apoptosis, enhanced Akt } \\
\text { activation and suppressed caspase-3, cytokine production }\end{array}$ & Alleviated neurological deficits & Wu et al.,2016 \\
\hline $\mathrm{SAH}$ & Mouse & $\begin{array}{l}\text { Reduced BBB disruption, edema and neuron apoptosis, } \\
\text { increased cerebral glucose uptake }\end{array}$ & Improved neurological functions & Pang et al., 2017 \\
\hline $\mathrm{SAH}$ & Mouse & $\begin{array}{l}\text { Suppressed JAK/STAT3 signaling, reduced M1 microglia } \\
\text { activation }\end{array}$ & $\begin{array}{l}\text { Attenuation of oxidative stress and } \\
\text { inflammation }\end{array}$ & Pang et al.,2018 \\
\hline $\begin{array}{l}\text { TBI } \\
\text { (closed head) }\end{array}$ & Mouse & $\begin{array}{l}\text { Reduction in oxidative stress (aconitase), neuronal } \\
\text { degeneration, cytokine release }\end{array}$ & Improved vestibulomotor function and memory & Lynch et al.,2005 \\
\hline $\begin{array}{l}\text { TBI } \\
\text { (closed head) }\end{array}$ & Mouse & Reduction in degenerating neurons, microgliosis & Improved vestibulomotor function and memory & $\begin{array}{l}\text { Laskowitz etal., } \\
\quad 2007\end{array}$ \\
\hline $\begin{array}{l}\text { TBI (cortical } \\
\text { contusion) }\end{array}$ & Rat & Smaller lesion volume, reduction in astrocytosis & Improved motor outcomes & Hoane et al.,2007 \\
\hline $\begin{array}{l}\text { TBI } \\
\text { (closed head } \\
\text { injury) }\end{array}$ & Mouse & Reduction in degenerating neurons, microgliosis, TNF & Improved vestibulomotor function & Wang et al.,2007 \\
\hline $\begin{array}{l}\text { TBI (cortical } \\
\text { contusion) }\end{array}$ & Rat & Reduction in degenerating neurons & $\begin{array}{l}\text { Improved sensorimotor function, reference, and } \\
\text { working memory }\end{array}$ & Hoane et al.,2009 \\
\hline $\begin{array}{l}\text { TBI } \\
\text { (closed head) }\end{array}$ & Mouse & $\begin{array}{l}\text { Suppressed activation of MMP-9, reduced breakdown of } \\
\text { blood-brain barrier, reduced TBI lesion volume and } \\
\text { vasogenic edema }\end{array}$ & $\begin{array}{l}\text { Decreased functional deficits compared } \\
\text { with saline-treated TBI animals }\end{array}$ & Cao et al.,2016 \\
\hline $\begin{array}{l}\text { TBI (closed } \\
\text { head) }\end{array}$ & Mouse & $\begin{array}{l}\text { Reduction in neuronal degeneration, microgliosis, and subset } \\
\text { of inflammatory genes }\end{array}$ & $\begin{array}{l}\text { Improved vestibulomotor function, } \\
\text { improved memory }\end{array}$ & $\begin{array}{l}\text { Laskowitz etal., } \\
2017\end{array}$ \\
\hline
\end{tabular}

feasibility of administering $\mathrm{CN}-105$ in a vulnerable patient population with acute brain injury which is often associated with polypharmacy. Importantly, this indication also allowed categorization of $\mathrm{CN}-105$ as an orphan drug. The initial trial open label trial was designed to establish safety and feasibility. Thus, we initiated the Proof of Concept Study to Evaluate $\mathrm{CN}-105$ in ICH Patients (CATCH) trial as a multi-site, open label, safety and feasibility trial (Fig. 2; NCT03168581). In addition to establishing safety and feasibility, CATCH was designed to establish molecular and radiographic markers of target engagement and surrogate markers of efficacy (length of ICU stay, development of intracranial hypertension, mortality, mRS at 30 and 90 days; Fig. 2). To evaluate target engagement, we included exploratory endpoints to assess the antiinflammatory activity that we observed in preclinical models. These include radiographic progression of relative and absolute perihematomal as defined by protocolized imaging studies at days $1,2,3$, and 5 and serum biomarkers of glial activation, neuronal injury, and inflammation, which were evaluated on a daily basis for the first week of treatment. We have enrolled 38 patients across 6 sites with no concerning safety signals. Based on these encouraging interim results, we have recently initiated a multicenter, randomized, double-blind, placebo-controlled clinical trial for patients with acute intracerebral hemorrhage in Singapore, the S-CATCH trial (NCT03711903).

Finally, participants in both clinical trials receive APOE genotyping to explore potential pharmacogenomic interactions of CN-105 on surrogate and clinical outcomes. Designed to characterize key methodologic variables, such as suitable timing of drug administration following injury, appropriate surrogate outcomes, and optimal duration of follow-up, taken together these early safety and feasibility phase studies will ultimately inform more definitive efficacy phase clinical trials. 


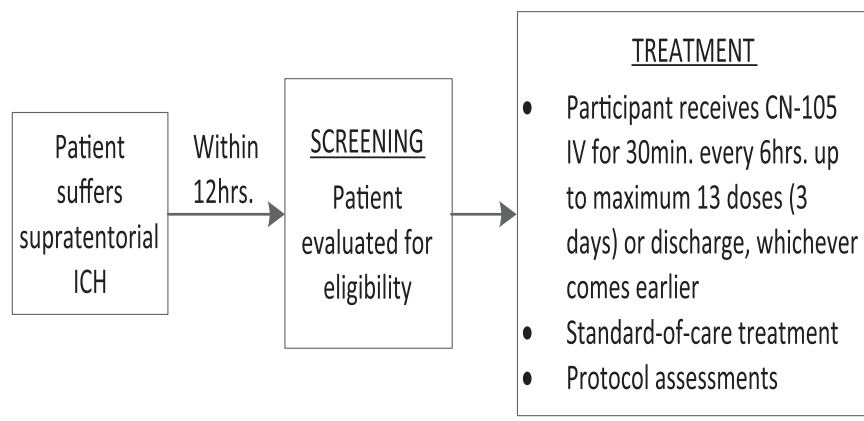

Fig. 2 The proof of Concept study to evAluate $\mathrm{CN}-105$ in inTraCerebral Hemmorrhage patients (CATCH) trial is a multi-site, open label, safety and feasibility trial (NCT03168581). Patients presenting within $12 \mathrm{~h}$ after supratentorial primary intracerebral hemorrhage are eligible for

\section{Postoperative Neuroprotection: the MARBLE Study}

CN-105's strong anti-inflammatory and neuroprotective mechanism of action represents a potential treatment for multiple forms of acute brain injury (blunt trauma, stroke, intracerebral and subarachnoid hemorrhage, and blast trauma), as well as more subacute processes associated with glial activation, neuroinflammation, and secondary neuronal injury. For example, perioperative neurocognitive disorders (PNDs) are common postoperative complications in older adults associated with increased 1-year mortality and long-term cognitive decline. One risk factor for worsened long-term postoperative cognitive trajectory is APOE4, which may elevate Alzheimer's disease risk partly by increasing neuroinflammation, also a theorized mechanism for PND. To address the potential for CN-105 to reduce CNS inflammatory mechanism following surgery, a phase 2 randomized placebocontrolled trial of $\mathrm{CN}-105$ in postoperative patients has been funded by the Alzheimer's Drug Discovery Foundation. The Modulating ApoE Signaling to Reduce Brain Inflammation, deLirium and postopErative Cognitive Dysfunction (MARBLE; NCT 03802396) study was designed as a single center, randomized, tiered, dose escalation study evaluating perioperative neurocognitive disorders in patients undergoing prolonged non-cardiac surgery. In addition to providing information on dosing, serial lumbar puncture will be performed to evaluate the effect of $\mathrm{CN}-105$ on cerebrospinal fluid markers of injury and inflammation and their correlation with a neurocognitive battery. The primary aim is safety, measured by adverse event rates in $\mathrm{CN}-105$ versus placebo-treated patients. Secondary aims include assessing the feasibility of perioperative $\mathrm{CN}-105$ administration and its efficacy for reducing postoperative neuroinflammation and PND risk and severity. Patients will receive either intravenous $\mathrm{CN}-105$ at $0.1,0.5$, or $1.0 \mathrm{mg} / \mathrm{kg}$ or placebo immediately before and every $6 \mathrm{~h}$ after surgery, for up to 3 days or 13 doses maximum. CN-105 efficacy will be assessed upon trial completion by comparing

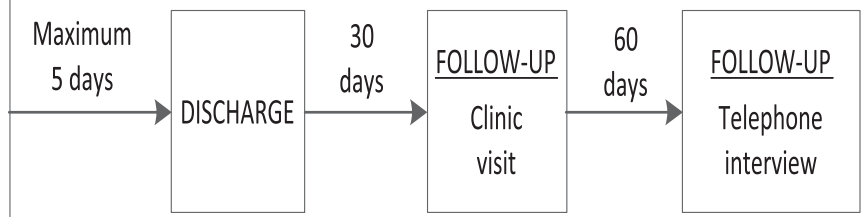

enrollment into the CATCH study. Participants are administered $\mathrm{CN}$ 105 at a dose of $1 \mathrm{mg} / \mathrm{kg}$ every $6 \mathrm{~h}$ for 3 days. Pharmacokinetics, serum protein, and radiographic biomarkers and clinical endpoints at 30 and 90 days after intracerebral hemorrhage were assessed

cognitive test results, delirium rates, and blood/CSF markers of neuroinflammation between the drug and placebo groups. Analysis will be stratified by CN-105 dose and by patient APOE genotype to account for pharmacogenomic effects. This study is currently recruiting patients.

\section{Conclusions}

Effective pharmacological interventions to improve functional outcomes after acute brain injury remain a compelling unmet medical need. Although maladaptive neuroinflammatory responses have long been recognized to contribute to secondary tissue injury, the development of apoE-based therapies represents the first reverse translation of an endogenous brain protein that is known to exert anti-inflammatory and neuroprotective effects. A wide literature supports that contention that apoE-based therapies may improve outcomes in preclinical models of acute and chronic brain injury. In particular, CN105 , a pentapeptide derived from the polar receptor-binding face of the apoE receptor has demonstrated efficacy across a wide variety of preclinical acute CNS injury models, has demonstrated safety in phase 1 study, and is now being tested in several phase 2 studies to evaluate efficacy after acute intracerebral hemorrhage and postoperative neuroprotection.

Acknowledgments The authors would like to acknowledge Sarah Laskowitz for providing artwork and editing.

\section{Compliance with Ethical Standards}

Disclosures DTL is an officer and has equity in Aegis-CN, which sponsored the clinical studies of CN-105. Duke University has equity and an intellectual property stake in $\mathrm{CN}-105$ and might benefit if proven effective and successful commercially. HW serves as a consultant for AegisCN. The CATCH trial was subsidized by orphan drug grant FDA FD-R-5387. MLJ serves as Principal Investigator for the CATCH trial and NIH/NINDS 1 R41 NS108821-01. Preclinical work was also supported by the Department of Defense grant CDMRP\#W81XWH-16-C-0142. 
MARBLE is supported by a Program to Accelerate Clinical Trials (PACT) grant from the Alzheimer's Drug Discovery Foundation.

\section{References}

1. Mozaffarian D, Benjamin EJ, Go AS, Arnett DK, Blaha MJ, Cushman M, et al. Heart disease and stroke statistics-2015 update: a report from the American Heart Association. Circulation 2015;131(4):e29-322.

2. Warner DS, James ML, Laskowitz DT, Wijdicks EF. Translational research in acute central nervous system injury: lessons learned and the future. JAMA Neurol 2014;71(10):1311-8.

3. Rincon F, Mayer SA. The epidemiology of intracerebral hemorrhage in the United States from 1979 to 2008. Neurocrit Care 2013;19(1):95-102.

4. Roozenbeek B, Maas AI, Menon DK. Changing patterns in the epidemiology of traumatic brain injury. Nat Rev Neurol 2013;9(4):231-6.

5. Mracsko E, Veltkamp R. Neuroinflammation after intracerebral hemorrhage. Front Cell Neurosci 2014;8:388.

6. Shichita T, Ito M, Yoshimura A. Post-ischemic inflammation regulates neural damage and protection. Front Cell Neurosci 2014;8: 319.

7. Geraghty JR, Davis JL, Testai FD. Neuroinflammation and Microvascular Dysfunction After Experimental Subarachnoid Hemorrhage: Emerging Components of Early Brain Injury Related to Outcome. Neurocrit Care 2019;31(2):373-89.

8. Ramlackhansingh AF, Brooks DJ, Greenwood RJ, Bose SK, Turkheimer FE, Kinnunen KM, et al. Inflammation after trauma: microglial activation and traumatic brain injury. Ann Neurol 2011;70(3):374-83.

9. Corps KN, Roth TL, McGavern DB. Inflammation and neuroprotection in traumatic brain injury. JAMA Neurol 2015;72(3):355-62.

10. Jacobowitz DM, Cole JT, McDaniel DP, Pollard HB, Watson WD. Microglia activation along the corticospinal tract following traumatic brain injury in the rat: a neuroanatomical study. Brain Res 2012;1465:80-9.

11. Jin X, Ishii H, Bai Z, Itokazu T, Yamashita T. Temporal changes in cell marker expression and cellular infiltration in a controlled cortical impact model in adult male C57BL/6 mice. PLoS One 2012;7(7):e41892.

12. Casault C, Al Sultan AS, Banoei M, Couillard P, Kramer A, Winston BW. Cytokine Responses in Severe Traumatic Brain Injury: Where There Is Smoke, Is There Fire? Neurocrit Care 2019;30(1):22-32.

13. Hernandez-Ontiveros DG, Tajiri N, Acosta S, Giunta B, Tan J, Borlongan CV. Microglia activation as a biomarker for traumatic brain injury. Front Neurol 2013;4:30.

14. Roberts I, Yates D, Sandercock P, Farrell B, Wasserberg J, Lomas $\mathrm{G}$, et al. Effect of intravenous corticosteroids on death within 14 days in 10008 adults with clinically significant head injury (MRC CRASH trial): randomised placebo-controlled trial. Lancet 2004;364(9442):1321-8.

15. McConeghy KW, Hatton J, Hughes L, Cook AM. A review of neuroprotection pharmacology and therapies in patients with acute traumatic brain injury. CNS Drugs 2012;26(7):613-36.

16. Kassam I, Gagnon F, Cusimano MD. Association of the APOEepsilon4 allele with outcome of traumatic brain injury in children and youth: a meta-analysis and meta-regression. J Neurol Neurosurg Psychiatry 2016;87(4):433-40.

17. Lawrence DW, Comper P, Hutchison MG, Sharma B. The role of apolipoprotein E episilon (epsilon)-4 allele on outcome following traumatic brain injury: A systematic review. Brain Inj 2015;29(9): $1018-31$.
18. Lanterna LA, Ruigrok Y, Alexander S, Tang J, Biroli F, Dunn LT, et al. Meta-analysis of APOE genotype and subarachnoid hemorrhage: clinical outcome and delayed ischemia. Neurology 2007;69(8):766-75.

19. Morris PG, Wilson JT, Dunn LT, Nicoll JA. Apolipoprotein E polymorphism and neuropsychological outcome following subarachnoid haemorrhage. Acta Neurol Scand 2004;109(3):205-9.

20. Biffi A, Anderson CD, Jagiella JM, Schmidt H, Kissela B, Hansen $\mathrm{BM}$, et al. APOE genotype and extent of bleeding and outcome in lobar intracerebral haemorrhage: a genetic association study. Lancet Neurol 2011;10(8):702-9.

21. Marini S, Crawford K, Morotti A, Lee MJ, Pezzini A, Moomaw CJ, et al. Association of Apolipoprotein E With Intracerebral Hemorrhage Risk by Race/Ethnicity: A Meta-analysis. JAMA Neurol 2019;76(4):480-91.

22. Weisgraber KH. Apolipoprotein E: structure-function relationships. Adv Protein Chem 1994;45:249-302.

23. Barger SW, Harmon AD. Microglial activation by Alzheimer amyloid precursor protein and modulation by apolipoprotein E. Nature 1997;388(6645):878-81.

24. Laskowitz DT, Goel S, Bennett ER, Matthew WD. Apolipoprotein E suppresses glial cell secretion of TNF alpha. J Neuroimmunol 1997;76(1-2):70-4.

25. Khovidhunkit W, Kim MS, Memon RA, Shigenaga JK, Moser AH, Feingold KR, et al. Effects of infection and inflammation on lipid and lipoprotein metabolism: mechanisms and consequences to the host. J Lipid Res 2004;45(7):1169-96.

26. Wang Y, Zhu X, Wu G, Shen L, Chen B. Effect of lipid-bound apoA-I cysteine mutants on lipopolysaccharide-induced endotoxemia in mice. J Lipid Res 2008;49(8):1640-5.

27. Barter PJ, Nicholls S, Rye KA, Anantharamaiah GM, Navab M, Fogelman AM. Antiinflammatory properties of HDL. Circ Res 2004;95(8):764-72.

28. Harris HW, Grunfeld C, Feingold KR, Rapp JH. Human very low density lipoproteins and chylomicrons can protect against endotoxin-induced death in mice. J Clin Invest 1990;86(3):696702 .

29. Levine DM, Parker TS, Donnelly TM, Walsh A, Rubin AL. In vivo protection against endotoxin by plasma high density lipoprotein. Proc Natl Acad Sci U S A 1993;90(24):12040-4.

30. Chuang K, Elford EL, Tseng J, Leung B, Harris HW. An expanding role for apolipoprotein E in sepsis and inflammation. Am J Surg 2010;200(3):391-7.

31. Laskowitz DT, Lee DM, Schmechel D, Staats HF. Altered immune responses in apolipoprotein E-deficient mice. J Lipid Res 2000;41(4):613-20.

32. de Bont N, Netea MG, Demacker PN, Verschueren I, Kullberg BJ, van Dijk KW, et al. Apolipoprotein E knock-out mice are highly susceptible to endotoxemia and Klebsiella pneumoniae infection. J Lipid Res 1999;40(4):680-5.

33. Lynch JR, Tang W, Wang H, Vitek MP, Bennett ER, Sullivan PM, et al. APOE genotype and an ApoE-mimetic peptide modify the systemic and central nervous system inflammatory response. J Biol Chem 2003;278(49):48529-33.

34. Van Oosten M, Rensen PC, Van Amersfoort ES, Van Eck M, Van Dam AM, Breve JJ, et al. Apolipoprotein E protects against bacterial lipopolysaccharide-induced lethality. A new therapeutic approach to treat gram-negative sepsis. J Biol Chem 2001;276(12): $8820-4$.

35. James ML, Blessing R, Bennett E, Laskowitz DT. Apolipoprotein E modifies neurological outcome by affecting cerebral edema but not hematoma size after intracerebral hemorrhage in humans. J Stroke Cerebrovasc Dis 2009;18(2):144-9.

36. Moretti EW, Morris RW, Podgoreanu M, Schwinn DA, Newman MF, Bennett E, et al. APOE polymorphism is 
associated with risk of severe sepsis in surgical patients. Crit Care Med 2005;33(11):2521-6.

37. Ely EW, Girard TD, Shintani AK, Jackson JC, Gordon SM, Thomason JW, et al. Apolipoprotein E4 polymorphism as a genetic predisposition to delirium in critically ill patients. Crit Care Med 2007;35(1):112-7.

38. Zhou W, Xu D, Peng X, Zhang Q, Jia J, Crutcher KA. Metaanalysis of APOE4 allele and outcome after traumatic brain injury. J Neurotrauma 2008;25(4):279-90.

39. Gao J, Wang H, Sheng H, Lynch JR, Warner DS, Durham L, et al. A novel apoE-derived therapeutic reduces vasospasm and improves outcome in a murine model of subarachnoid hemorrhage. Neurocrit Care 2006;4(1):25-31.

40. James ML, Sullivan PM, Lascola CD, Vitek MP, Laskowitz DT. Pharmacogenomic effects of apolipoprotein e on intracerebral hemorrhage. Stroke 2009;40(2):632-9.

41. Lei B, Mace B, Bellows ST, Sullivan PM, Vitek MP, Laskowitz DT, et al. Interaction between sex and apolipoprotein e genetic background in a murine model of intracerebral hemorrhage. Transl Stroke Res 2012;3(1):94-101.

42. Ophir G, Amariglio N, Jacob-Hirsch J, Elkon R, Rechavi G, Michaelson DM. Apolipoprotein E4 enhances brain inflammation by modulation of the NF-kappaB signaling cascade. Neurobiol Dis 2005;20(3):709-18.

43. Laskowitz DT, Vitek MP. Apolipoprotein E and neurological disease: therapeutic potential and pharmacogenomic interactions. Pharmacogenomics 2007;8(8):959-69.

44. Misra UK, Adlakha CL, Gawdi G, McMillian MK, Pizzo SV, Laskowitz DT. Apolipoprotein E and mimetic peptide initiate a calcium-dependent signaling response in macrophages. J Leukoc Biol 2001;70(4):677-83.

45. Guttman M, Prieto JH, Handel TM, Domaille PJ, Komives EA. Structure of the minimal interface between ApoE and LRP. J Mol Biol 2010;398(2):306-19.

46. Croy JE, Brandon T, Komives EA. Two apolipoprotein E mimetic peptides, ApoE(130-149) and ApoE(141-155)2, bind to LRP1. Biochemistry 2004;43(23):7328-35.

47. Martin AM, Kuhlmann C, Trossbach S, Jaeger S, Waldron E, Roebroek A, et al. The functional role of the second NPXY motif of the LRP1 beta-chain in tissue-type plasminogen activatormediated activation of N-methyl-D-aspartate receptors. J Biol Chem 2008;283(18):12004-13.

48. Qiu Z, Crutcher KA, Hyman BT, Rebeck GW. ApoE isoforms affect neuronal N-methyl-D-aspartate calcium responses and toxicity via receptor-mediated processes. Neuroscience 2003;122(2): 291-303.

49. Sheng Z, Prorok M, Brown BE, Castellino FJ. N-methyl-Daspartate receptor inhibition by an apolipoprotein E-derived peptide relies on low-density lipoprotein receptor-associated protein. Neuropharmacology 2008;55(2):204-14.

50. Pocivavsek A, Mikhailenko I, Strickland DK, Rebeck GW. Microglial low-density lipoprotein receptor-related protein 1 modulates c-Jun N-terminal kinase activation. J Neuroimmunol 2009;214(1-2):25-32.

51. Ma Q, Zhao Z, Sagare AP, Wu Y, Wang M, Owens NC, et al. Blood-brain barrier-associated pericytes internalize and clear aggregated amyloid-beta42 by LRP1-dependent apolipoprotein E isoform-specific mechanism. Mol Neurodegener 2018;13(1):57.

52. Bell RD, Winkler EA, Singh I, Sagare AP, Deane R, Wu Z, et al. Apolipoprotein E controls cerebrovascular integrity via cyclophilin A. Nature 2012;485(7399):512-6.

53. Laskowitz DT, Thekdi AD, Thekdi SD, Han SK, Myers JK, Pizzo $\mathrm{SV}$, et al. Downregulation of microglial activation by apolipoprotein E and apoE-mimetic peptides. Exp Neurol 2001;167(1):74-85.

54. Sabo T, Lomnitski L, Nyska A, Beni S, Maronpot RR, Shohami E, et al. Susceptibility of transgenic mice expressing human apolipoprotein $\mathrm{E}$ to closed head injury: the allele E3 is neuroprotective whereas E4 increases fatalities. Neuroscience 2000;101(4): 879-84.

55. Mesis RG, Wang H, Lombard FW, Yates R, Vitek MP, Borel CO, et al. Dissociation between vasospasm and functional improvement in a murine model of subarachnoid hemorrhage. Neurosurg Focus 2006;21(3):E4.

56. Aono M, Bennett ER, Kim KS, Lynch JR, Myers J, Pearlstein RD, et al. Protective effect of apolipoprotein E-mimetic peptides on Nmethyl-D-aspartate excitotoxicity in primary rat neuronal-glial cell cultures. Neuroscience 2003;116(2):437-45.

57. Aono M, Lee Y, Grant ER, Zivin RA, Pearlstein RD, Warner DS, et al. Apolipoprotein E protects against NMDA excitotoxicity. Neurobiol Dis 2002;11(1):214-20.

58. Lee Y, Aono M, Laskowitz D, Warner DS, Pearlstein RD. Apolipoprotein E protects against oxidative stress in mixed neuronal-glial cell cultures by reducing glutamate toxicity. Neurochem Int 2004;44(2): 107-18.

59. Chen Y, Durakoglugil MS, Xian X, Herz J. ApoE4 reduces glutamate receptor function and synaptic plasticity by selectively impairing ApoE receptor recycling. Proc Natl Acad Sci U S A 2010;107(26):12011-6

60. Hoe HS, Pocivavsek A, Chakraborty G, Fu Z, Vicini S, Ehlers MD, et al. Apolipoprotein E receptor 2 interactions with the N-methyl-Daspartate receptor. J Biol Chem 2006;281(6):3425-31.

61. Linton MF, Gish R, Hubl ST, Butler E, Esquivel C, Bry WI, et al. Phenotypes of apolipoprotein B and apolipoprotein E after liver transplantation. J Clin Invest 1991;88(1):270-81.

62. Laskowitz DT, Fillit H, Yeung N, Toku K, Vitek MP. Apolipoprotein E-derived peptides reduce CNS inflammation: implications for therapy of neurological disease. Acta Neurol Scand Suppl 2006; 185:15-20.

63. Hoane MR, Kaufman N, Vitek MP, McKenna SE. COG1410 improves cognitive performance and reduces cortical neuronal loss in the traumatically injured brain. J Neurotrauma 2009;26(1):121-9.

64. Hoane MR, Pierce JL, Holland MA, Birky ND, Dang T, Vitek MP, et al. The novel apolipoprotein E-based peptide COG1410 improves sensorimotor performance and reduces injury magnitude following cortical contusion injury. J Neurotrauma 2007;24(7): 1108-18.

65. Kaufman NA, Beare JE, Tan AA, Vitek MP, McKenna SE, Hoane MR. COG1410, an apolipoprotein E-based peptide, improves cognitive performance and reduces cortical loss following moderate fluid percussion injury in the rat. Behav Brain Res 2010;214(2): 395-401.

66. Laskowitz DT, Song P, Wang H, Mace B, Sullivan PM, Vitek MP, et al. Traumatic brain injury exacerbates neurodegenerative pathology: improvement with an apolipoprotein E-based therapeutic. J Neurotrauma 2010;27(11):1983-95.

67. Lynch JR, Wang H, Mace B, Leinenweber S, Warner DS, Bennett $\mathrm{ER}$, et al. A novel therapeutic derived from apolipoprotein $\mathrm{E}$ reduces brain inflammation and improves outcome after closed head injury. Exp Neurol 2005;192(1):109-16.

68. Lei B, James ML, Liu J, Zhou G, Venkatraman TN, Lascola CD, et al. Neuroprotective pentapeptide $\mathrm{CN}-105$ improves functional and histological outcomes in a murine model of intracerebral hemorrhage. Sci Rep 2016;6:34834.

69. Liu J, Zhou G, Kolls BJ, Tan Y, Fang C, Wang H, et al. Apolipoprotein E mimetic peptide $\mathrm{CN}-105$ improves outcome in a murine model of SAH. Stroke Vasc Neurol 2018;3(4):222-30.

70. Pang J, Chen Y, Kuai L, Yang P, Peng J, Wu Y, et al. Inhibition of Blood-Brain Barrier Disruption by an Apolipoprotein E-Mimetic Peptide Ameliorates Early Brain Injury in Experimental Subarachnoid Hemorrhage. Transl Stroke Res 2017;8(3):257-72.

71. Pang J, Peng J, Matei N, Yang P, Kuai L, Wu Y, et al. Apolipoprotein E Exerts a Whole-Brain Protective Property by 
Promoting M1? Microglia Quiescence After Experimental Subarachnoid Hemorrhage in Mice. Transl Stroke Res 2018;9(6): 654-68.

72. Wu Y, Pang J, Peng J, Cao F, Vitek MP, Li F, et al. An apoE-derived mimic peptide, COG1410, alleviates early brain injury via reducing apoptosis and neuroinflammation in a mouse model of subarachnoid hemorrhage. Neurosci Lett 2016;627:92-9.

73. McAdoo JD, Warner DS, Goldberg RN, Vitek MP, Pearlstein R, Laskowitz DT. Intrathecal administration of a novel apoE-derived therapeutic peptide improves outcome following perinatal hypoxicischemic injury. Neurosci Lett 2005;381(3):305-8.

74. Tu TM, Kolls BJ, Soderblom EJ, Cantillana V, Ferrell PD, Moseley $\mathrm{MA}$, et al. Apolipoprotein E mimetic peptide, CN-105, improves outcomes in ischemic stroke. Ann Clin Transl Neurol 2017;4(4): 246-65.

75. Tukhovskaya EA, Yukin AY, Khokhlova ON, Murashev AN, Vitek MP. COG1410, a novel apolipoprotein-E mimetic, improves functional and morphological recovery in a rat model of focal brain ischemia. J Neurosci Res 2009;87(3):677-82.

76. Wang H, Anderson LG, Lascola CD, James ML, Venkatraman TN, Bennett ER, et al. ApolipoproteinE mimetic peptides improve outcome after focal ischemia. Exp Neurol 2013;241:67-74.
77. Cao F, Jiang Y, Wu Y, Zhong J, Liu J, Qin X, et al. Apolipoprotein E-Mimetic COG1410 Reduces Acute Vasogenic Edema following Traumatic Brain Injury. J Neurotrauma 2016;33(2):175-82.

78. Laskowitz DT, Wang H, Chen T, Lubkin DT, Cantillana V, Tu TM, et al. Neuroprotective pentapeptide $\mathrm{CN}-105$ is associated with reduced sterile inflammation and improved functional outcomes in a traumatic brain injury murine model. Sci Rep 2017;7:46461.

79. Wang H, Durham L, Dawson H, Song P, Warner DS, Sullivan PM, et al. An apolipoprotein E-based therapeutic improves outcome and reduces Alzheimer's disease pathology following closed head injury: evidence of pharmacogenomic interaction. Neuroscience 2007;144(4):1324-33.

80. Guptill JT, Raja SM, Boakye-Agyeman F, Noveck R, Ramey S, Tu TM, et al. Phase 1 Randomized, Double-Blind, Placebo-Controlled Study to Determine the Safety, Tolerability, and Pharmacokinetics of a Single Escalating Dose and Repeated Doses of CN-105 in Healthy Adult Subjects. J Clin Pharmacol 2017;57(6):770-6.

Publisher's Note Springer Nature remains neutral with regard to jurisdictional claims in published maps and institutional affiliations. 